Publication Trends in Personality and Individual Differences, 1980-2018

\author{
Gregory D. Webster, Imani N. Turner, Joy E. Losee, \\ Elizabeth A. Mahar, and Val Wongsomboon \\ University of Florida
}

Submitted to PAID: May 30, 2018

Rejected by PAID: September 6, 2018

Minor revisions made: July 2, 2020

Final version for PsyArXiv: July 2, 2020

\begin{abstract}
Author Note
Corresponding author: Gregory D. Webster, Department of Psychology, University of Florida, P.O. Box 112250, Gainesville, FL 32611-2250. E-mail: gdwebs@ufl.edu
\end{abstract}




\begin{abstract}
An analysis including 679 articles from the journal Personality and Individual Differences (PAID) investigated trends from 1980 to 2018. Time periods were separated into three groups: $1980-1984,2000$, and 2018. First, the number of title words per article was examined, which showed a linear increase over time. Second, the most frequent words per PAID article were investigated over time. The most frequent title words across three time points were, predictably, "personality," "individual," and "differences." Title word frequencies also unveiled trends such as the adoption of the Big Five and Dark Triad traits, and an increasing interest in latent modeling of personality traits. Third, we explored the number of authors per article, which showed a linear increase across the three time points. Lastly, we identified the most-cited articles from 1980 to 2018. Themes from some of the most influential articles included scale development, scale and construct comparisons, review articles, and innovative methods. Although personality psychology has some constant themes over time, these findings suggest that it continues to be an influential and dynamic field open to incorporating emerging topics and evolving trends over time.
\end{abstract}

Keywords: Publication trends; Personality; Individual differences; Meta-science; Titles 


\section{Publication Trends in Personality and Individual Differences, 1980-2018}

\section{Introduction}

The journal Personality and Individual Differences (PAID) has been publishing cutting-edge empirical research since 1980 . As $P A I D$ approaches its $40^{\text {th }}$ year of publishing in 2019, it is time to take stock of publication trends in the field that can be gleaned from the articles it publishes. What can we learn about the topics that personality researchers study by examining article titles over time? And what can we learn about the researchers themselves? Have research teams increased in number over time? And which researchers have published the most highly-cited articles in PAID? The present research aims to address these and other questions by studying changes in PAID characteristics between 1980 and 2018.

\subsection{Publication trends in psychology, personality, and related fields}

Personality psychology is a key contributor to the broader field of psychology, and its influence appears to be growing. For example, a review of nearly half a million articles indexed in Psychological Abstracts (via the PsycINFO database) showed that articles including at least some mention of personality or individual differences grew from $14 \%$ in $1975-1980$ to $17 \%$ in $1985-1989$-a modest increase of $20 \%$ (Angleitner, 1991). To better understand publication trends within personality psychology, we can look to its foremost journals.

To be sure, the focal journal of the present review-PAID—is just a single outlet in a tapestry of journals that form the fabric of empirical research in personality and individual differences. Other prominent journals include those focusing primarily on personality (e.g., Journal of Personality [JP], Journal of Research in Personality [JRP], 
European Journal of Personality, Journal of Personality and Social Psychology [JPSP]: Personality Processes and Individual Differences [PPID]), those focusing on personality assessment (e.g., Assessment, Psychological Assessment, Journal of Personality Assessment), and those that publish personality alongside social psychology (e.g., JPSP, Personality and Social Psychology Bulletin [PSPB], Personality and Social Psychology Review, Social Psychological and Personality Science). To our knowledge, reviews of publication trends have been performed for $J R P, P S P B$, and $J P S P$ (sometimes combined with $J P$ ).

A review of article title words published in $J R P$ from 1973 to 2012 used Wordle (http://wordle.net) to examine title word frequencies and produce word clouds-a data visualization whereby words are clustered together and word sizes reflects their relative frequency (Webster, 2013). Over the course of 40 years, the title word personality increased fivefold in terms of title word frequency per $J R P$ article, from $6.2 \%$ to $31.7 \%$. The title word social nearly doubled from $3.8 \%$ to $6.5 \%$ of articles. With the advent of the Five Factor Model and the Big Five personality traits, title words including Big, Five, and Five-Factor debuted in the top 10 title words around the middle of the years surveyed. Self-esteem also nearly doubled over time, from $2.5 \%$ to $4.6 \%$. In contrast, the title word trait, which relates to much personality research, was prominent and stable over time. A related analysis of title words in posters presented at the annual meeting of the Society for Personality and Social Psychology showed that personality ranked in the top 10 in frequency in 2005, but only the top 25 in 2009 (Webster \& Nichols, 2009); however, such an observed change over only four years may be due to sampling error more so than any "true" change. 
A review of publication trends in $P S P B$ between 1976 and 1996 showed increases in (a) number of authors per article from 1.63 to 2.64 (an increase of 1.01 or $62 \%$ ), (b) articles focusing on personality and individual differences from $30 \%$ to $34 \%$ (an increase of 13\%), and (d) uses of correlation, multiple regression, factor analysis, path analysis, and structural equation modeling (SEM) methods (Sherman, Buddie, Dragan, End, \& Finney, 1999).

A review of over $500 J P S P$ articles from 1968, 1978, and 1988 found that, regarding methods, correlation, multiple regression, factor analysis, path analysis and SEM all increased substantially between 1968 and 1988 (Reis \& Stiller, 1992). Authors per JPSP article also increased from 2.01 in 1968 to 2.51 in 1988 , an increase of $1 / 2$ an author or $25 \%$; for PPID, the overall mean was 2.41 authors. Number of words in JPSP titles grew from 9.77 in 1968 to 11.45 in 1988, an increase of 12/3 words or $17 \%$; for PPID, the overall mean was 11.60 title words.

Specifically among PPID articles, between 1968 and 1988, the percent of both self-reports (36 to 90\%) and behavioral ratings (7 to 21\%) increased (West, Newsom, and Fenaughty, 1992). During the same period, (a) longitudinal designs increased (o to 6\%), (b) true experiments increased (o to 25\%), (c) quasi experiments decreased (6 to o\%), (d) cross-sectional designs decreased (44 to 31\%), and (e) experimental designs that featured at least one personality variable (e.g., person-situation interactions) decreased (38 to 28\%) in PPID articles (West et al., 1992). This last result may contrast with a more recent Google Scholar review (1978-2007) showing that the phrase person-situation interaction had eclipsed the phrase person-situation debate both in terms of overall frequency and growth rate over time (Webster, 2009). 
A review of $J P S P$ articles from 1966 to 2002 showed that articles including individual differences increased over time from about 50\% in 1966-1967 to about $67 \%$ in 2002; however, this growth was nonlinear because individual differences reached a nadir of near 30\% around 1977 (Swann \& Seyle, 2005). JPSP's reorganization into three sections in 1980-with one section reserved for personality research (PPID)-helped boost individual differences research over time. Unsurprisingly, personality traits were the most-frequently-studied type of individual difference, and their share increased slightly between $1966-1967$ and 2002 from about $25 \%$ to about $27 \%$.

A bibliometric analysis of articles published in JPSP from 1965 to 2000 revealed a wealth of key trends (Quiñones-Vidal, Loźpez-García, Peñaranda-Ortega, \& TortosaGil, 2004). For example, the most-highly-cited works cited in JPSP articles were often key methodological papers (e.g., Baron \& Kenny's [1986] seminal moderator-mediator work), broad theoretical papers (e.g., Festinger's [1954] “A theory of social comparison processes”), or scale-development papers (e.g., Watson, Clark, \& Tellegen’s [1988] Positive and Negative Affect Scales [PANAS]). Number of authors per JPSP article increased from 1.85 in 1965 to 3.18 in 2002, an increase of $1 \frac{1 / 3}{3}$ authors (72\%).

A review of publication trends that examined articles published in both $J P$ and JPSP: PPID in 1997, 2002, and 2007 found that the percent of articles claiming (or implying) to study behavior was 16,19 , and $17 \%$, respectively (Furr, 2009). Thus, personality psychologists clearly value studying behavior, but it's reflected in only between one-fifth and one-sixth of studies in the field's top journals.

A more specific review of nearly 500 abstracts focusing on articles that examined both personality and romantic relationships (1932-2001) found that $84 \%$ of studies used cross-sectional designs (76\% exclusively so), 17\% used longitudinal designs, and 
$6 \%$ used experimental or quasi-experimental designs ( $3 \%$ used other designs; Cooper \& Sheldon, 2002). Over time, longitudinal designs increased and cross-sectional decreased. Studies relying exclusively on self-report data also increased over time.

We may also gain some insight into recent topical trends in personality psychology by examining how personality handbook chapters (nodes) are linked by the citations they share in common (ties) using two-mode citation network analysis (Clifton \& Webster, 2017). For example, using 74 chapters in the SAGE Handbook of Personality and Individual Differences (Zeigler-Hill \& Shackelford, 2018), a series of network-based cluster analyses showed sets of chapters linked by empirical communities studying (a) measurement, (b) narcissism, (c) threat and disease, and (d) meta-theory and development, with a chapter on developmental person-by-situation interactions being among the most central nodes (Lanning, Baron, \& Webster, 2019). Another cluster analysis sorted chapters into empirical communities focusing on (a) pathology, (b) assessment, and (c) general topics, with chapters on aggression and personality pathologies being the most central (Lanning et al., 2019).

\subsection{The present review}

In the present study, we review publication trends in PAID from 1980 to 2018 through the use of (a) the number of title words, (b) most frequently used title words, (c) number of authors per article, and (d) most-cited articles. The number of title words per article may reflect the complexity of the research questions or how much detail authors choose to disclose to readers up front. The most frequent title words likely reflect topics of interests in personality psychology. Changes in number of authors per article likely reflect changing norms in the size of research teams. The most frequently cited articles reveal the most influential articles in PAID over the last few decades. 


\section{Method}

\subsection{Sample}

On May 8, 2018, we sampled 679 PAID articles from the Web of Science online database for the years 1980-1984 $(n=221), 2000(n=180)$, and $2018(n=278)$. We had originally planned to sample 1980 (PAID's inaugural year), 1999, and 2018 (i.e., 19year intervals); however, too few articles were published in 1980 to allow for reliable estimates. Thus, we expanded the first time window to five years (1980-1984) with a mean of 1982, and an average time-window interval of 18 years (i.e., 1982, 2000, 2018). Overall, this sample included information on title words and number of authors.

We also sought data on which PAID articles were the most frequently cited, irrespective of publication year. To this end, again using the Web of Science database, we also identified the top PAID articles in terms of citations and citations per year.

\subsection{Analyses}

We used the online application Wordle.net to make word clouds and produce words frequencies for analyses.

To analyze change-over-time trends in number of authors and words in titles per article, we used the psych package for R (Revelle, 2018). Because both outcomesauthors and title words per article-were count variables, we anticipated positively skewed residual distributions, which violate the normality assumption of general linear modeling. To normalize residuals, we used square-root transformations for both variables (i.e., $x^{1 / 2}$ ) prior to analysis (see McClelland, 2014; see also Judd, McClelland, \& Ryan, 2017). We examined two-step regression models to determine (a) the extent to which linear growth over time occurred (Step 1) and (b) whether this growth was strictly linear by also testing quadratic effects (Step 2). 


\section{Results}

\subsection{Title words over time}

\subsubsection{Number of title words}

Table 1 (left half) shows the descriptive statistics for numbers of words in titles per article across the three sampled time windows. In a simple regression, the (square root of) number of title words per article grew substantially over linear time ( $b=0.016$, $t_{677}=10.67, p<.001, r=.38,95 \%$ CI $\left.[.31, .44]\right)$. In a multiple regression, which added the quadratic effect of time, again produced a substantial simple linear effect $(b=0.016$, $\left.t_{676}=10.53, p<.001, r_{\mathrm{p}}=.38,95 \% \mathrm{CI}[.31, .44]\right)$, but only a trivial quadratic effect $(b=$ $\left.0.00015, t_{676}=0.92, p=.36, r_{\mathrm{p}}=.04,95 \% \mathrm{CI}[-.04, .11]\right)$. Consequently, growth in title words over time was fairly linear, and we used the simple, linear model to produce predicted means for 1982 (i.e., the midpoint of 1980-1984), 2000, and 2018, which, respectively, were $9.27,11.15$, and 13.20 title words per article. In other words, numbers of words article titles increased by about $42 \%$ or nearly four words on average between 1982 and 2018.

\subsubsection{Most-frequent title words}

Table 2 and Figure 1 show the most-frequent title words per PAID article across all three time windows. Perhaps unsurprisingly, the top word in each of the three time periods was personality. The words individual, differences, and individual-differences were often among the most-frequent title words used by PAID authors during the sampled periods. Thus, the journal title Personality and Individual Differences seems remarkably apt given the article titles it publishes. Other title words that appeared among the top 30 (or so) most-frequent ones across all three time windows were intelligence, behavio(u)r, and social. This finding suggests that presenting research on 
intelligence, actual behavior, and social phenomena have been - and continue to bemainstays of $P A I D$ since its inception.

Among words that appeared in two of the three time windows, scale, factor, and anxiety increased slightly between 1980-1984 and 2000, but were absent from 2018's list. To be sure, scale development, refinement, and structure continue to be important to personality psychologists; however, it could be that PAID is publishing comparatively fewer of these articles lately, perhaps focusing instead on examining relations among traits and behaviors with established scales. Anxiety research has likely been largely supplanted by studies on neuroticism-or its inverse, emotional stability-since the field began adopting the Five-Factor Model of personality (McCrae \& Costa, 1987). The title word trait increased slightly between 1980-1984 and 2018, yet was curiously absent from 2000's top list. Just as in the past, much of PAID's published research remains rooted in trait-based personality and individual differences.

Several title words absent from 1980-1984's top list debuted in 2000 and decreased slightly in 2018: model, analysis, students, adolescents, emotional, and depression. The 2000 debuts of both model and analysis may relate to the field's focus on data analysis and model testing during the past 20 years (e.g., confirmatory factor analysis, structural equations modeling). The sample-specific title words students and adolescents could reflect either an increase in describing samples in article titles or the adoption of longitudinal methods to examine personality development over the lifespan. The later emergences of the title words emotional and depression may reflect the field's increasing integration with-or perhaps influence on-affective science and abnormal or clinical psychology. 
Finally, among the title words debuting in 2018's most-frequent list were traits, dark, triad, narcissism, self-esteem, life, satisfaction, women, and cognitive. If we combine the tallies for both trait and traits in 2018, then they reflect about $13.7 \%$ of all recent title words, again showing PAID's increased emphasis on personality traits. The title words dark and triad both debut among 2018's most frequent, owing to an increase in the field's interest in so-called "dark" personality traits such as the Dark Triad (or Tetrad) traits: psychopathy, narcissism, Machiavellianism (and sometimes greed, spite, or sadism; Chabrol, Van Leeuwen, Rodgers, \& Séjourné, 2009; Marcus \& Zeigler-Hill, 2015; Paulhus \& Williams, 2002). That narcissism also debuts as a frequent title word in 2018 further supports this notion (Turner \& Webster, 2018). The likely-related title words life and satisfaction also debut in 2018, hinting at an increased interest in studying life satisfaction as an outcome and the traits that relate to it. The 2018 debuts of women and cognitive among the most frequent title words may respectively reflect (a) an interest in describing samples in article titles and (b) a delayed influence of psychology's cognitive revolution (Miller, 2003) on the psychology of personality and individual differences.

\subsubsection{Big Five traits}

Table 3 (top) shows the title-word frequencies per PAID article of the Big Five personality traits. In 1980-1984, only the three NEO traits-neuroticism, extraversion, and openness-appear, which stands to reason given that NEO measures (e.g., Costa \& McCrae, 1978) existed prior to those for the Big Five (e.g., John \& Srivastava, 1999). Nevertheless, even though the Big Five traits were being assessed and studied both independently and as a set by 2000 , the three NEO traits continued to dominate PAID article titles. By 2018, however, all Big Five traits appeared in title words. Often the first 
factor to emerge in structural analyses of the Big Five traits, extraversion was (in 19801984) and remains (in 2018) the most frequent trait appearing in PAID article title words. Between 1980-1984 and 2018, extraversion and neuroticism decreased in frequency, openness remained the same, and agreeableness and conscientiousness increased.

\subsubsection{Dark Triad traits}

As mentioned above, the past decade or so has seen a groundswell of interest in "dark" personality traits. Table 3 (middle) shows the title-word frequencies per PAID article of the Dark Triad traits-psychopathy, narcissism, and Machiavellianism. In 1980-1984 and 2000, only psychopathy appeared in PAID article title words, likely owing to its longstanding interdisciplinary roots that span personality, abnormal, and clinical psychology as well as psychiatry. In contrast, by 2018, all three Dark Triad traits appear in titles, with narcissism playing a leading role. Comparing these traits over time, psychopathy's relative loss has been narcissism's relative gain, whereas Machiavellianism currently appears to be the least-studied of the Dark Triad traits.

\subsubsection{Methodology}

Regarding methodological trends expressed via article title words per PAID article (Table 3, bottom), latent increased fairly linearly over time, suggesting that PAID authors have become more interested in modeling latent (vs. measured) traits and other constructs. The title word longitudinal has appeared in fewer article titles over time, showing a drop in frequency from 1980-1984 to 2000, but no change from 2000 to 2018. This is mildly surprising because personality psychology appears to have increasingly emphasized development methods over the past decade, which often includes longitudinal designs. Perhaps related words or phrases such as temporal, over 
time, and multi-wave have been replacing longitudinal in titles. Despite a slight dip in 2000, studies with genetic-focused titles continue to play an important role in PAID articles from 1980-1984 to 2018-a trend that appears to be consistent with the field of personality psychology. Finally, when comparing title word frequencies from 19801984 to 2018 , words relating to validity and reliability continue to play a fairly consistent role in PAID articles, with the former being more frequent than the latter, perhaps because there are more varieties of validity than reliability.

\subsection{Authors over time}

Table 1 (right half) shows the descriptive statistics for authors per article across the three sampled time windows. In a simple regression, the (square root of) number authors per article grew substantially over linear time $\left(b=0.013, t_{677}=12.85, p<.001, r\right.$ $=.44,95 \% \mathrm{CI}[.38, .50])$. In a multiple regression, which added the quadratic effect of time, again produced a substantial simple linear effect $\left(b=0.013, t_{676}=12.89, p<.001\right.$, $r_{\mathrm{p}}=.44,95 \%$ CI $\left.[.38, .5 \mathrm{O}]\right)$, but only a trivial quadratic effect $\left(b=-0.00011, t_{676}=-1.01\right.$, $\left.p=.31, r_{\mathrm{p}}=-.04,95 \% \mathrm{CI}[-.11, .04]\right)$. Consequently, growth in authors per article over time was fairly linear, and we used the simple, linear model to produce predicted means for 1982, 2000, and 2018, which were 1.87, 2.56, and 3.37 authors per article. Thus, authors per article increased by about $80 \%$ or $1 \frac{1 / 2}{2}$ authors on average between 1982 and 2018.

\subsection{Highly-cited articles}

Using Web of Science, we also identified the most-cited articles published in PAID between 1980 and May 8, 2018 (all-inclusive; no time windows). Table 4 shows the top 32 PAID articles with 300 or more citations. Because citations are count data, they tend to have highly positively skewed frequencies distributions, which is the norm 
(e.g., Duffy, Jadidian, Webster, \& Sandell, 2011). Some themes emerging from this list of influential articles include scale development or refinement studies, comparisons of competing measures of the same construct, links between two frequently-studied constructs, review articles, and innovative methods (e.g., fit indices for SEMs).

Because articles accumulate citations over time, older articles are more likely to be highly cited than newer ones. Thus, we also identified the PAID articles with the highest citations per year. Table 5 shows the top 24 PAID articles-those with 20 or more citations per year. Although Tables 4 and 5 share some considerable overlap, some different themes that emerged in Table 5 (vs. Table 4) included a meta-analytic (vs. narrative) review and at least three articles focusing on social media (e.g., Facebook). As one might expect given that older articles have more time to be cited, the median publication year in Table 4 was older $(M d n=1998, M=1996.6, S D=8.3)$, than the same in Table $5(M d n=2005, M=2003 \cdot 3, S D=7.5)$, which examined citations counts adjusted for publication year.

Regarding the authors of highly-cited articles, there appear to be two sets of outstanding contributors (Tables 4 and 5). First, at least three members of the Eysenck family are featured-some multiple times. Given H.J. and S.B.G. Eysenck's service as editors for $P A I D$, this is hardly surprising, notwithstanding H.J. Eysenck's notoriety as a controversial researcher of intelligence (Carl \& Woodley of Menie, 2019). Second, Costa and McCrae also enjoy multiple highly-cited entries. As shown here-and likely in other personality journals as well-their teamwork on the NEO and Five-Factor model has been among the most influential research in the field over the last few decades.

\section{Discussion}


During its first four decades, PAID's articles titles became longer (more words per title) and its research teams became larger (more authors per article). These trends are largely consistent with related fields and journals, which have seen similar increases over time in both words per title and authors per articles (e.g., Reis \& Stiller, 1992). Thus, PAID appears to be part of a larger movement in science toward publishing more nuanced, complex, transparent, informative titles (resulting in more words) for articles written by larger research teams.

Regarding changes in the frequencies of title words over time, a few coherent themes emerged. First, the PAID remains aptly named; personality, individual, and differences are among the most-frequent title words and are consistent over time. Second, whereas the three NEO traits were the most frequent of the Big Five traits to appear in article titles in the early 1980 s and in 2000, all five Big Five traits appeared in titles by 2018. Third, mentions of the Dark Triad increased rapidly between 2000 and 2018, but in comparative terms, between the early 1980 s and 2018, narcissism increased in title words whereas psychopathy decreased. Factors contributing to the Dark Triad's rapid rise likely include its establishment as a theoretical construct of interrelated traits (Paulhus \& Williams, 2002), the advent of brief measures of it (Jonason \& Webster, 2010; Jones \& Paulhus, 2014; Webster \& Jonason, 2013), and its intersections with popular culture (Jonason, Webster, Li, Schmitt, \& Crysel, 2012). Finally, regarding methodology, researchers appeared to be focusing more on latent constructs over time, whereas interest in genetics, validity, and reliability remained largely constant. Unexpectedly, and counter to some prior reviews of personality research, frequencies of the word longitudinal decreased in PAID article titles over time. 
The increase in authors per article could be due to a number of factors. First, the advent of the Internet has enabled collaborations unrestrained by physical distances. The rapidity of electronic mail and large file sharing have ushered in a new era that often fosters collaboration across regions, nations, and continents. Second, like other fields, the process of authoring scientific articles may be undergoing a period of increased specialization. For example, in 1980, the same principal investigator might design the study, collect and analyze the data, and write the manuscript for publication. In contrast, in 2018, three colleagues might choose to divide the work to suit their respective strengths. Perhaps one designs the study, collects the data, and writes the Method section; a second analyzes the data and writes the Results section; and a third who is a seasoned expert in theory-crafting writes the Introduction and Discussion sections. Third, the publish-or-perish pressure often cultivated by academic promotion and tenure requirements helps to incentivize collaborative projects. For example, one researcher working alone might produce a single sole-authored article a year, but two people working on each other's projects together might produce two articles a year-one lead-authored and one co-authored-thus doubling one's output. Finally, some modern research projects are simply more ambitious and comprehensive than those undertaken in 1980. For example, a multi-wave developmental or behavioral-genetics study will likely require multiple authors with specialized skills.

One possible consequence of having more authors per article may be longer articles. For example, a review of article length in 24 primary journals published by the American Psychological Association (e.g. JPSP) from 1986 to 2005 found that average article length increased significantly overall, but that the rate of growth was decreasing (Webster, 2007). One contributing factor to this increase in article length may be the 
explosion of references and citations that have co-occurred with the growth in article length (Adair \& Vohra, 2003). Although purely speculative, it could be that including more authors-especially those with more unique training backgrounds or different areas of expertise-could inadvertently result in longer articles with more varied or interdisciplinary reference lists.

Lastly, we examined which PAID articles had the highest citation counts throughout the journal's existence (1980-2018). Among the most-highly-cited articles were those developing, refining, or comparing scales or those developing new goodnessof-fit indices. Regarding the authors themselves, the teams of Costa and McCrae, as well as a few members of the Eysenck family, authored multiple, highly-cited articles in PAID.

\subsection{Limitations}

As with any analysis of publication trends in a given journal, this review provides readers with few representative snapshots, rather than a complete film with hundreds of frames. To truly obtain a clearer picture, we'd have to assess every article published in PAID from 1980 to 2018, which would likely prove unwieldy. Nevertheless, we feel that analyzing title words and author counts from three time periods averaging 18 years apart can provide some insights into the topics that personality researchers are studying and publishing in $P A I D$, the average sizes of those research teams, and how both of these change over time.

In particular, title words can occasionally paint an inaccurate picture of the article that follows them; however, we have little reason to doubt that most article titles do indeed reflect the major themes or constructs examined in their respective articles. Of course, a more thorough method might involve a comprehensive text analysis of all 
words in every article published in PAID. But we feel that looking at title words alone can provide a more efficient and effective way to detect the major themes and topics in personality, especially when averaged across hundreds of articles.

In defense of using title words, we can examine publication trends in a related field to see if the personality trends observed for PAID articles are interdisciplinarily consistent. For example, an analysis of title words and citation counts in the journal Evolution and Human Behavior from 1979 to 2008 showed that the most-frequent title words were indeed those that most researchers would associate with evolutionary psychology (in descending order): human, sex, evolutionary, sexual, attractiveness and differences (tie), behavior, male, evolution, and selection (Webster, Jonason, \& Schember, 2009). This pattern is consistent with what we found for PAID titles: words relating closely to personality-including personality and individual and differenceswere indeed the most frequent.

Although useful and straightforward, citation counts are an inherently imperfect measure of an article's "true" influence on other researchers. For example, once a goodness-of-fit index has become commonplace, authors tend to stop citing its source because it has become accepted as common knowledge. Citation counts also fail to account for the diversity of the citing sources. For example, imagine two articles published in PAID in the same year with equal citation counts. Article A is widely cited among personality researchers, whereas Article B is cited among some personality researchers, but also among economists, sociologists, educational and developmental psychologists, and the medical and health sciences. In this case, most would argue that Article B has been more influential than Article A, despite their equal citation counts. In addition, some articles are simply "sleepers" or "late bloomers"; they aren’t fully 
appreciated-or cited-by other researchers until several years after they're initially published. Finally, citation counts don't reflect whether researchers are citing the article to praise it or denounce it. For example, some retracted articles continue to garner citations out of infamy rather than true influence. Despite these flaws, citation counts remain a simple metric that provides a useful indicator of article influence.

\subsection{Conclusions}

What can be gleaned from this review of publication trends in PAID during its near-40 years of existence? First, numbers of words per title increased by about four words or $42 \%$. Second, numbers of authors per article increased by about $1 \frac{1 / 2}{2}$ or $80 \%$. Third, broadly speaking, changes in title-word frequency appear to reflect general changes in the field of personality, including an increased focus on the Big Five traits, the Dark Triad traits, traits in general, and assessing latent traits. PAID article titles consistently reflected high interest in intelligence and social phenomena over time, perhaps showing personality psychology's continued mutual influence with intelligence assessment and social psychology. In addition, the most-highly-cited articles were those focusing on developing, revising, or comparing scales or fit indices-helpful tools that can be harnessed by other researchers. We hope that this review of publication trends in PAID will provide researchers not only with a window into the journal's past, but also a glimpse into personality psychology's possible futures. 


\section{References}

Adair, J. G., \& Vohra, N. (2003). The explosion of knowledge, references, and citations: Psychology's unique response to a crisis. American Psychologist, 58, 15-23.

Angleitner, A. (1991). Personality psychology: Trends and developments. European Journal of Personality, 5, 185-197. doi:10.1002/per.2410050302

Baron, R. M., \& Kenny, D. A. (1986). The moderator-mediator variable distinction in social psychological research: Conceptual, strategic, and statistical considerations. Journal of Personality and Social Psychology, 51, 1173-1182. doi:10.1037/0022-3514.51.6.1173

Carl, N., \& of Menie, M. A. W. (2019). A scientometric analysis of controversies in the field of intelligence research. Intelligence, 77, 101397. doi:10.1016/j.intell.2019.101397

Chabrol, H., Van Leeuwen, N., Rodgers, R., \& Séjourné, N. (2009). Contributions of psychopathic, narcissistic, Machiavellian, and sadistic personality traits to juvenile delinquency. Personality and Individual Differences, 47, 734-739. doi:10.1016/j.paid.2009.06.020

Clifton, A. D., \& Webster, G. D. (2017). An introduction to social network analysis for personality and social psychologists. Social Psychological and Personality Science, 8, 442-453. doi:10.1177/1948550617709114

Cooper, M. L., \& Sheldon, M. S. (2002). Seventy years of research on personality and close relationships: Substantive and methodological trends over time. Journal of Personality, 70, 783-812. doi:10.1111/1467-6494.05024 
Costa, P. T., \& McCrae, R. R. (1978). Objective personality assessment. In M. Storandt, I. C. Siegler, \& M. F. Elisa (Eds.), The clinical psychology of aging (pp. 119-143). Boston, MA: Springer.

Duffy, R. D., Jadidian, A., Webster, G. D., \& Sandell, K. J. (2011). The research productivity of academic psychologists: Assessment, trends, and best practice recommendations. Scientometrics, 89, 207-227. doi:10.1007/s11192-011-0452-4

Festinger, L. (1954). A theory of social comparison processes. Human Relations, 7, 114140. doi:10.1177/001872675400700202

Furr, R. M. (2009). Personality psychology as a truly behavioural science. European Journal of Personality, 23, 369-401. doi:10.1002/per.724

John, O. P., \& Srivastava, S. (1999). The Big-Five trait taxonomy: History, measurement, and theoretical perspectives. In L. A. Pervin \& O. P. John (Eds.), Handbook of personality: Theory and research (Vol. 2, pp. 102-138). New York: Guilford.

Jonason, P. K., \& Webster, G. D. (2010). The Dirty Dozen: A concise measure of the Dark Triad. Psychological Assessment, 22, 420-432. doi:10.1037/a0019265

Jonason, P. K., Webster, G. D., Li, N. P., Schmitt, D., \& Crysel, L. C. (2012). The rise of the antihero in popular culture: A life history theory of the Dark Triad. Review of General Psychology, 16, 192-199. doi:10.1037/a0027914

Jones, D. N., \& Paulhus, D. L. (2014). Introducing the short dark triad (SD3) a brief measure of dark personality traits. Assessment, 21, 28-41. doi:10.1177/1073191113514105

Judd, C. M., McClelland, G. H., \& Ryan, C. S. (2017). Data analysis: A model comparison approach (3rd ed.). New York: Routledge. 
Lanning, K., Baron, S., \& Webster, G. D. (2019). The network structure of personality psychology: What the Sage Handbook of Personality and Individual Differences tells us about the nature of the field. In V. Zeigler-Hill \& T. Shakelford (Eds.), Sage Handbook of personality and individual differences: The Science of Personality and Individual Differences (pp. 384-404). Thousand Oaks, CA: Sage.

Marcus, D. K., \& Zeigler-Hill, V. (2015). A big tent of dark personality traits. Social and Personality Psychology Compass, 9, 434-446. doi:10.1111/spc3.12185

McClelland, G. H. (2014). Nasty data: Unruly, ill-mannered observations can ruin your analysis. In H. T. Reis \& C. M. Judd (Eds.), Handbook of research methods in social and personality psychology (2nd ed., pp. 608-626). New York: Cambridge University Press.

McCrae, R. R., \& Costa, P. T. (1987). Validation of the five-factor model of personality across instruments and observers. Journal of Personality and Social Psychology, 52, 81-90. doi:10.1037/0022-3514.52.1.81

Miller, G. A. (2003). The cognitive revolution: a historical perspective. Trends in Cognitive Sciences, 7, 141-144. doi:10.1016/S1364-6613(03)0oo29-9

Paulhus, D. L., \& Williams, K. M. (2002). The Dark Triad of personality: Narcissism, Machiavellianism, and psychopathy. Journal of Research in Personality, 36, 556-563. doi:10.1016/Soo92-6566(02)00505-6

Quiñones-Vidal, E., Loźpez-García, J. J., Peñaranda-Ortega, M., \& Tortosa-Gil, F. (2004). The nature of social and personality psychology as reflected in JPSP, 1965-2000. Journal of Personality and Social Psychology, 86, 435-352. doi:10.1037/0022-3514.86.3.435 
Reis, H. T., \& Stiller, J. (1992). Publication trends in JPSP: A three-decade review. Personality and Social Psychology Bulletin, 18, 465-472. doi:10.1177/0146167292184011

Revelle, W. (2018) psych: Procedures for personality and psychological research, Northwestern University, Evanston, Illinois, USA. https://CRAN.Rproject.org $/$ package $=$ psych Version $=1.8 .4$.

Sherman, R. C., Buddie, A. M., Dragan, K. L., End, C. M., \& Finney, L. J. (1999). Twenty years of PSPB: Trends in content, design, and analysis. Personality and Social Psychology Bulletin, 25, 177-187. doi:10.1177/0146167299025002004

Swann, W. B., Jr., \& Seyle, C. (2005). Personality psychology's comeback and its emerging symbiosis with social psychology. Personality and Social Psychology Bulletin, 31, 155-165. doi:10.1177/0146167204271591

Turner, I. N., \& Webster, G. D. (2018). Narcissism and dark personality traits. In T. Hermann, A. Brunell, \& J. Foster (Eds.), The handbook of trait narcissism: Key advances, research methods, and controversies (pp. 195-204). New York: Springer.

Watson, D., Clark, L. A., \& Tellegen, A. (1988). Development and validation of brief measures of positive and negative affect: The PANAS scales. Journal of Personality and Social Psychology, 54, 1063-1070. doi:10.1037/0022$3514 \cdot 54.6 .1063$

Webster, G. D. (2007). The demise of the increasingly protracted APA journal article? American Psychologist, 62, 255-257. doi:10.1037/0003-066X.62.3.255

Webster, G. D. (2009). The person-situation interaction is increasingly outpacing the person-situation debate in the scientific literature: A 30-year analysis of 
publication trends, 1978-2007. Journal of Research in Personality, 43, 278-279. doi:10.1016/j.jrp.2008.12.030

Webster, G. D. (2013, February). "Personality" rises to the top: 40 years of $J R P$ titles, 1973-2012. P: The Online Newsletter for Personality Science (Issue 7). https://www.personality-arp.org/html/newslettero7/jrp_titles.html

Webster, G. D., \& Jonason, P. K. (2013). Putting the "IRT" in "dirty": Item response theory analyses of the Dark Triad Dirty Dozen-an efficient measure of narcissism, psychopathy, and Machiavellianism. Personality and Individual Differences, 54, 302-306. doi:10.1016/j.paid.2012.08.027

Webster, G. D., Jonason, P. K., \& Schember, T. O. (2009). Hot topics and popular papers in evolutionary psychology: Analyses of title words and citation counts in Evolution and Human Behavior, 1979-2008. Evolutionary Psychology, 7, 348362. doi:10.1177/147470490900700301

Webster, G. D., \& Nichols, A. L. (2009, Spring). Trends and hot topics in personality and social psychology: An analysis of SPSP poster title words from 2005 and 2009. Dialogue, 24(1), 16-19. http://spsp.org/sites/default/files/dialogue241.pdf

West, S. G., Newsome, J. T., \& Fenaughty, A. M. (1992). Publication trends in JPSP: Stability and change in topics, methods, and theories across two decades. Personality and Social Psychology Bulletin, 18, 473-484. doi:10.1177/0146167292184012

Zeigler-Hill, V., \& Shackelford, T. K. (Eds.). (2018). The SAGE handbook of personality and individual differences. Thousand Oaks, CA: SAGE. 
Table 1. Descriptive statistics for title words and authors per article in PAID over time

\begin{tabular}{|c|c|c|c|c|c|c|}
\hline & \multicolumn{3}{|c|}{ Title words per article } & \multicolumn{3}{|c|}{ Authors per article } \\
\hline & $1980-1984$ & 2000 & $2018^{\mathrm{a}}$ & $1980-1984$ & 2000 & $2018^{a}$ \\
\hline Mean & 9.84 & 11.23 & 13.62 & 1.95 & 2.81 & 3.55 \\
\hline$S D$ & 4.07 & 4.20 & 4.20 & 0.94 & 1.41 & 1.76 \\
\hline Min & 3 & 4 & 4 & 1 & 1 & 1 \\
\hline$M d n$ & 9 & 11 & 13 & 2 & 2 & 3 \\
\hline Max & 26 & 27 & 27 & 7 & 9 & 10 \\
\hline
\end{tabular}

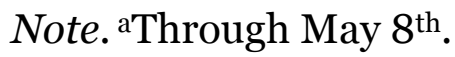


Table 2. Top title words frequencies per $P A I D$ article across three time periods

\begin{tabular}{|c|c|c|c|c|c|c|c|c|}
\hline \multicolumn{3}{|c|}{$1980-1984$} & \multicolumn{3}{|c|}{2000} & \multicolumn{3}{|c|}{2018 (through May 8) } \\
\hline Rank & Title word & $\%$ & Rank & Title word & $\%$ & Rank & Title word & $\%$ \\
\hline 1.0 & personality & 22.2 & 1.0 & personality & 18.3 & 1.0 & personality & 18.0 \\
\hline 2.0 & extraversion & 10.0 & 4.0 & differences & 7.2 & 2.0 & differences & 9.7 \\
\hline 3.0 & individual-differences & 6.8 & 4.0 & emotional & 7.2 & 3.0 & traits & 8.6 \\
\hline 4.0 & intelligence & 5.0 & 4.0 & factor & 7.2 & 4.0 & relationship & 8.3 \\
\hline 5.0 & psychoticism & 4.5 & 4.0 & scale & 7.2 & 5.0 & role & 7.9 \\
\hline 8.0 & effects & 4.1 & 4.0 & social & 7.2 & 6.0 & individual & 6.5 \\
\hline 8.0 & factor & 4.1 & 7.0 & inventory & 6.7 & 7.0 & emotional & 6.1 \\
\hline 8.0 & scale & 4.1 & 9.0 & intelligence & 6.1 & 8.0 & intelligence & 5.8 \\
\hline 8.0 & seeking & 4.1 & 9.0 & students & 6.1 & 9.5 & dark & $5 \cdot 4$ \\
\hline 8.0 & sensation & 4.1 & 9.0 & validity & 6.1 & 9.5 & social & $5 \cdot 4$ \\
\hline 13.0 & children & 3.6 & 11.5 & analysis & 5.6 & 11.0 & trait & 5.0 \\
\hline 13.0 & dimensions & 3.6 & 11.5 & structure & 5.6 & 12.0 & study & 4.7 \\
\hline 13.0 & measures & 3.6 & 14.5 & adolescents & 5.0 & 13.5 & self-esteem & $4 \cdot 3$ \\
\hline 13.0 & neuroticism & 3.6 & 14.5 & anxiety & 5.0 & 13.5 & triad & $4 \cdot 3$ \\
\hline 13.0 & theory & 3.6 & 14.5 & questionnaire & 5.0 & 16.0 & adolescents & 4.0 \\
\hline 16.0 & anxiety & 3.2 & 14.5 & study & 5.0 & 16.0 & analysis & 4.0 \\
\hline 16.0 & behavio(u)r & 3.2 & 19.0 & coping & 4.4 & 16.0 & life & 4.0 \\
\hline 16.0 & function & 3.2 & 19.0 & individual & 4.4 & 19.5 & behavio(u)r & 3.6 \\
\hline 16.0 & response & 3.2 & 19.0 & relationship & $4 \cdot 4$ & 19.5 & cognitive & 3.6 \\
\hline 16.0 & trait & 3.2 & 19.0 & reliability & 4.4 & 19.5 & effects & 3.6 \\
\hline 20.5 & arousal & 2.7 & 19.0 & role & 4.4 & 19.5 & narcissism & 3.6 \\
\hline 20.5 & control & 2.7 & 23.0 & depression & $3 \cdot 9$ & 19.5 & students & 3.6 \\
\hline 20.5 & electrodermal & 2.7 & 23.0 & model & $3 \cdot 9$ & 19.5 & women & 3.6 \\
\hline 20.5 & factors & 2.7 & 23.0 & sample & 3.9 & 24.5 & associated & 3.2 \\
\hline 20.5 & impulsiveness & 2.7 & 27.0 & academic & $3 \cdot 3$ & 24.5 & depression & 3.2 \\
\hline 20.5 & performance & 2.7 & $27 \cdot 0$ & behavio(u)r & $3 \cdot 3$ & 24.5 & satisfaction & 3.2 \\
\hline 20.5 & questionnaire & 2.7 & 27.0 & correlates & $3 \cdot 3$ & 24.5 & two & 3.2 \\
\hline 20.5 & social & 2.7 & 27.0 & motivation & $3 \cdot 3$ & 29.0 & approach & 2.9 \\
\hline $27 \cdot 5$ & factor-analysis & 2.3 & 27.0 & symptoms & $3 \cdot 3$ & 29.0 & beliefs & 2.9 \\
\hline 27.5 & influence & 2.3 & & & & 29.0 & model & 2.9 \\
\hline 27.5 & schizotypy & 2.3 & & & & 29.0 & relation & 2.9 \\
\hline 27.5 & task & 2.3 & & & & 29.0 & sensitivity & 2.9 \\
\hline
\end{tabular}

Note. 1980-1984: 221 articles, 2116 words. 2000: 180 articles, 2019 words. 2018: 278 articles, 3777 words. 
Table 3. Title words frequencies per PAID article (\%) over time: Specific comparisons

\begin{tabular}{lccc}
\hline \multicolumn{1}{c}{ Title word } & $1980-1984$ & 2000 & $2018^{\mathrm{a}}$ \\
\hline Big Five traits & & & \\
Extraversion & 10.0 & 1.1 & 1.8 \\
Neuroticism & 3.6 & 2.8 & 0.7 \\
Openness & 0.5 & 1.1 & 0.7 \\
Agreeableness & 0.0 & 0.0 & 0.7 \\
Conscientiousness & 0.0 & 0.0 & 0.4 \\
Dark Triad traits & & & \\
Psychopathy & 1.8 & 0.6 & 0.7 \\
Narcissism & 0.0 & 0.0 & 3.6 \\
Machiavellianism & 0.0 & 0.0 & 0.4 \\
Methodologies & & & \\
Longitudinal & 1.4 & 0.6 & 0.7 \\
Latent & 0.0 & 0.6 & 1.1 \\
Genetics & 1.8 & 0.6 & 2.2 \\
Validity & 3.2 & 7.8 & 4.0 \\
Reliability & 0.5 & 5.0 & 0.4 \\
\hline
\end{tabular}

Note. 1980-1984: 221 articles, 2116 words. 2000: 180 articles, 2019 words. 2018: 278 articles, 3777 words.

aThrough May $8^{\text {th }}$.

bIncludes title words gene(s), genetic(s), and genotype(s).

cIncludes title words valid, validity, validate, and validation.

dIncludes title words reliable and reliability. 
Table 4. Articles in published in PAID with 400 or more citations

$\begin{array}{llll}\text { Rank Citations } & \text { Year } \quad \text { Author(s) Title }\end{array}$

\begin{tabular}{|c|c|c|c|c|}
\hline 1 & 1687 & 1985 & $\begin{array}{l}\text { Eysenck, S.B.G, } \\
\text { Eysenck, H.J., and }\end{array}$ & $\begin{array}{l}\text { A revised version of the Psychoticism } \\
\text { Scale }\end{array}$ \\
\hline 2 & 1440 & 2001 & Whiteside and Lynam & $\begin{array}{l}\text { The Five Factor Model and } \\
\text { impulsivity: Using a structural mode } \\
\text { of personality to understand } \\
\text { impulsivity }\end{array}$ \\
\hline 3 & 996 & 1998 & $\begin{array}{l}\text { Schutte, Malouff, } \\
\text { Hall, Haggerty, } \\
\text { Cooper, Golden, and } \\
\text { Dornheim }\end{array}$ & $\begin{array}{l}\text { Development and validation of a } \\
\text { measure of emotional intelligence }\end{array}$ \\
\hline 4 & 736 & 1994 & $\begin{array}{l}\text { Haidt, Mccauley, and } \\
\text { Rozin }\end{array}$ & $\begin{array}{l}\text { Individual-differences in sensitivity } \\
\text { to disgust - a scale sampling } 7 \\
\text { domains of disgust elicitors }\end{array}$ \\
\hline 5 & 677 & 1985 & $\begin{array}{l}\text { Eysenck, S.B.G., } \\
\text { Pearson, Easting, and } \\
\text { Allsopp }\end{array}$ & $\begin{array}{l}\text { Age norms for impulsiveness, } \\
\text { venturesomeness and empathy in } \\
\text { adults }\end{array}$ \\
\hline 6 & 649 & 2007 & Barrett & $\begin{array}{l}\text { Structural equation modelling: } \\
\text { Adjudging model fit }\end{array}$ \\
\hline 7 & 641 & 1992 & Costa and McCrae & 4 ways 5 factors are basic \\
\hline 8 & 548 & 2001 & $\begin{array}{l}\text { Torrubia, Avila, } \\
\text { Molto, and Caseras }\end{array}$ & $\begin{array}{l}\text { The Sensitivity to Punishment and } \\
\text { Sensitivity to Reward Questionnaire } \\
\text { (SPSRQ) as a measure of Gray's } \\
\text { anxiety and impulsivity dimensions }\end{array}$ \\
\hline 9 & 530 & 1993 & $\begin{array}{l}\text { Frost, Heimberg, } \\
\text { Holt, Mattia, and } \\
\text { Neubauer }\end{array}$ & $\begin{array}{l}\text { A comparison of } 2 \text { measures of } \\
\text { perfectionism }\end{array}$ \\
\hline 10 & 514 & 1994 & $\begin{array}{l}\text { Freeston, Rhéaume, } \\
\text { Letarte, Dugas, and } \\
\text { Ladouceur }\end{array}$ & Why do people worry? \\
\hline 11 & 476 & 1991 & $\begin{array}{l}\text { Costa, McCrae, and } \\
\text { Dye }\end{array}$ & $\begin{array}{l}\text { Facet scales for agreeableness and } \\
\text { conscientiousness - a revision of the } \\
\text { NEO Personality-Inventory }\end{array}$ \\
\hline 12 & 472 & 2007 & Steiger & $\begin{array}{l}\text { Understanding the limitations of } \\
\text { global fit assessment in structural } \\
\text { equation modeling }\end{array}$ \\
\hline
\end{tabular}


$13463 \quad 1980$ Hare

Stanford, Mathias, $\quad$ Fifty years of the Barratt

14
3572004 Matud

3481984 Claridge and Broks

Walach, Buchheld, Buttenmuller, Kleinknecht, and Schmidt

3351994 Arnett

3332007 Bentler

Petrides and Furnham
A research scale for the assessment of psychopathy in criminal populations

Impulsiveness Scale: An update and review

Dimensions of impulsive behavior:

Personality and behavioral measures

Negative life events, cognitive emotion regulation and emotional problems

Reliability and validity of a brief measure of sensation seeking

A critical evaluation of the emotional intelligence construct

Dimensions of personality $-16,5$ or 3 - criteria for a taxonomic paradigm

4 ways 5 factors are not basic

Gender differences in stress and coping styles

Schizotypy and hemisphere function. 1. Theoretical considerations and the measurement of schizotypy

Measuring mindfulness - the Freiburg Mindfulness Inventory (FMI)

Sensation seeking - a new conceptualization and a new scale

On tests and indices for evaluating structural models

On the dimensional structure of emotional intelligence 
$27 \quad 320 \quad 1986 \quad$ Furnham

$28 \quad 313 \quad 1998 \quad$ Craig

$29 \quad 305 \quad 2004 \quad$ McCrae and Costa

$30 \quad 302 \quad 1981$ Launay and Slade

$31301 \quad 1995$ Mason, Claridge, and

$32 \quad 300 \quad 2003$ Lopes, Salovey, and Straus
Response bias, social desirability and dissimulation

The relationship among bullying, victimization, depression, anxiety, and aggression in elementary school children

A contemplated revision of the NEO Five-Factor Inventory

The measurement of hallucinatory predisposition in male and female prisoners

New scales for the assessment of schizotypy

Emotional intelligence, personality, and the perceived quality of social relationships

Note. As of May 8, 2018. 
Table 5. Articles in published in PAID with 20 or more citations per year

\begin{tabular}{|c|c|c|c|c|}
\hline Rank & $\begin{array}{l}\text { Citations } \\
\text { per year }\end{array}$ & Year & Author(s) & Title \\
\hline 1.0 & 80.00 & 2001 & Whiteside and Lynam & $\begin{array}{l}\text { The Five Factor Model and } \\
\text { impulsivity: Using a structural model } \\
\text { of personality to understand } \\
\text { impulsivity }\end{array}$ \\
\hline 2.0 & 54.08 & 2007 & Barrett & $\begin{array}{l}\text { Structural equation modelling: } \\
\text { Adjudging model fit }\end{array}$ \\
\hline 3.0 & 49.62 & 1985 & $\begin{array}{l}\text { Eysenck, S.B.G. } \\
\text { Eysenck, H.J., and } \\
\text { Barrett }\end{array}$ & $\begin{array}{l}\text { A revised version of the Psychoticism } \\
\text { Scale }\end{array}$ \\
\hline 4.0 & 47.43 & 1998 & $\begin{array}{l}\text { Schutte, Malouff, Hall, } \\
\text { Haggerty, Cooper, } \\
\text { Golden, and Dornheim }\end{array}$ & $\begin{array}{l}\text { Development and validation of a } \\
\text { measure of emotional intelligence }\end{array}$ \\
\hline 5.0 & $44 \cdot 70$ & 2009 & $\begin{array}{l}\text { Stanford, Mathias, } \\
\text { Dougherty, Lake, } \\
\text { Anderson, and Patton }\end{array}$ & $\begin{array}{l}\text { Fifty years of the Barratt } \\
\text { Impulsiveness Scale: An update and } \\
\text { review }\end{array}$ \\
\hline 6.0 & 39.43 & 2012 & $\begin{array}{l}\text { Nadkarni and } \\
\text { Hofmann }\end{array}$ & Why do people use Facebook? \\
\hline 7.0 & $39 \cdot 33$ & 2007 & Steiger & $\begin{array}{l}\text { Understanding the limitations of } \\
\text { global fit assessment in structural } \\
\text { equation modeling }\end{array}$ \\
\hline 8.0 & 33.77 & 2006 & $\begin{array}{l}\text { Reynolds, Ortengren, } \\
\text { Richards, and De Wit }\end{array}$ & $\begin{array}{l}\text { Dimensions of impulsive behavior: } \\
\text { Personality and behavioral measures }\end{array}$ \\
\hline 9.0 & 30.44 & 2001 & $\begin{array}{l}\text { Torrubia, Avila, Molto, } \\
\text { and Caseras }\end{array}$ & $\begin{array}{l}\text { The Sensitivity to Punishment and } \\
\text { Sensitivity to Reward Questionnaire } \\
\text { (SPSRQ) as a measure of Gray's } \\
\text { anxiety and impulsivity dimensions }\end{array}$ \\
\hline 10.0 & 29.44 & 1994 & $\begin{array}{l}\text { Haidt, McCauley, and } \\
\text { Rozin }\end{array}$ & $\begin{array}{l}\text { Individual-differences in sensitivity } \\
\text { to disgust - a scale sampling } 7 \\
\text { domains of disgust elicitors }\end{array}$ \\
\hline 11.0 & 27.75 & 2007 & Bentler & $\begin{array}{l}\text { On tests and indices for evaluating } \\
\text { structural models }\end{array}$ \\
\hline 12.0 & 27.22 & 2010 & $\begin{array}{l}\text { Martins, Ramalho, and } \\
\text { Morin }\end{array}$ & $\begin{array}{l}\text { A comprehensive meta-analysis of } \\
\text { the relationship between emotional } \\
\text { intelligence and health }\end{array}$ \\
\hline
\end{tabular}




\begin{tabular}{|c|c|c|c|c|}
\hline 13.0 & 26.46 & 2006 & $\begin{array}{l}\text { Walach, Buchheld, } \\
\text { Buttenmuller, } \\
\text { Kleinknecht, and } \\
\text { Schmidt }\end{array}$ & $\begin{array}{l}\text { Measuring mindfulness - the } \\
\text { Freiburg Mindfulness Inventory } \\
\text { (FMI) }\end{array}$ \\
\hline 14.0 & 23.80 & 2004 & Matud & $\begin{array}{l}\text { Gender differences in stress and } \\
\text { coping styles }\end{array}$ \\
\hline 15.0 & 23.74 & 1992 & Costa and McCrae & 4 ways 5 factors are basic \\
\hline 16.5 & 23.50 & 2007 & $\begin{array}{l}\text { O'Connor and } \\
\text { Paunonen }\end{array}$ & $\begin{array}{l}\text { Big Five personality predictors of } \\
\text { post-secondary academic } \\
\text { performance }\end{array}$ \\
\hline 16.5 & 23.50 & 2013 & Seidman & $\begin{array}{l}\text { Self-presentation and belonging on } \\
\text { Facebook: How personality } \\
\text { influences social media use and } \\
\text { motivations }\end{array}$ \\
\hline 18.0 & 23.44 & 2001 & $\begin{array}{l}\text { Garnefski, Kraaij, and } \\
\text { Spinhoven }\end{array}$ & $\begin{array}{l}\text { Negative life events, cognitive } \\
\text { emotion regulation and emotional } \\
\text { problems }\end{array}$ \\
\hline 19.0 & 23.41 & 2002 & $\begin{array}{l}\text { Hoyle, Stephenson, } \\
\text { Palmgreen, Lorch, and } \\
\text { Donohew }\end{array}$ & $\begin{array}{l}\text { Reliability and validity of a brief } \\
\text { measure of sensation seeking }\end{array}$ \\
\hline 20.0 & 22.80 & 2014 & $\begin{array}{l}\text { Buckels, Trapnell, and } \\
\text { Paulhus }\end{array}$ & Trolls just want to have fun \\
\hline 21.0 & 21.00 & 2011 & $\begin{array}{l}\text { Eysenck, M.W. and } \\
\text { Derakshan }\end{array}$ & $\begin{array}{l}\text { New perspectives in attentional } \\
\text { control theory }\end{array}$ \\
\hline 22.0 & 20.56 & 1994 & $\begin{array}{l}\text { Freeston, Rhéaume, } \\
\text { Letarte, Dugas, and } \\
\text { Ladouceur }\end{array}$ & Why do people worry? \\
\hline 23.0 & 20.38 & 1993 & $\begin{array}{l}\text { Frost, Heimberg, Holt, } \\
\text { Mattia, and Neubauer }\end{array}$ & $\begin{array}{l}\text { A comparison of } 2 \text { measures of } \\
\text { perfectionism }\end{array}$ \\
\hline 24.0 & 20.33 & 2004 & McCrae and Costa & $\begin{array}{l}\text { A contemplated revision of the NEO } \\
\text { Five-Factor Inventory }\end{array}$ \\
\hline
\end{tabular}

Note. As of May 8, 2018. 


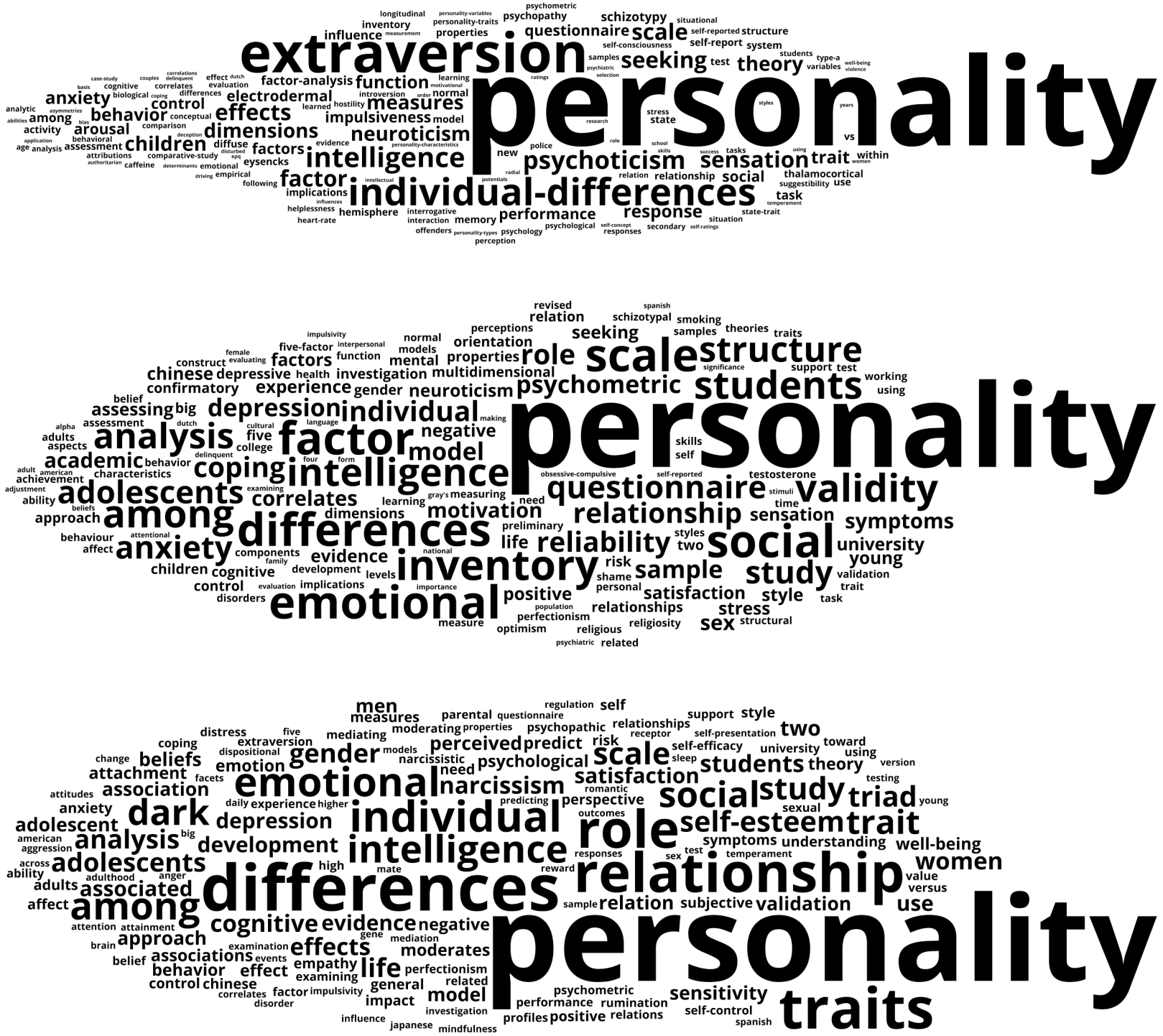

Figure 1. Title word clouds (via Wordle.net) for articles published in PAID in 19801984 (top), 2000 (middle), and 2018 (bottom); 150-word limit per cloud. 